BULLETIN (New Series) OF THE

AMERICAN MATHEMATICAL SOCIETY

Volume 38, Number 2, Pages 123-129

S 0273-0979(01)00893-X

Article electronically published on January 19, 2001

\title{
PORTRAIT OF ALEXANDER (1888-1971)
}

\author{
I. M. JAMES
}

The first half of the twentieth century was a golden age for Princeton mathematics. This was especially true of topology, and the prince of Princeton topologists for most of that time was James Waddell Alexander. What has hitherto been published about him (see [2], [5]) hardly does justice to one of the most interesting and important American mathematicians of that period. The available material is not only scanty and fragmentary but also quite hard to find. The following short memoir will, I hope, go some way towards filling the gap 1

Among the forbears of the mathematician, three in particular stand out. A great, great, great grandfather, James Waddell, was a famous blind preacher who led the migration of thousands of Ulster Scots into the Shenandoah Valley of Virginia in the early eighteenth century and helped organize many Presbyterian churches and schools for his people. A great, great grandfather, Archibald Alexander, was the first professor and principal of the Princeton Theological Seminary from its foundation in 1812 until his death in 1851. In Princeton Alexander Road and, on the campus, two separate Alexander Halls are named after him. His eldest son, James Waddell Alexander, was also a leading member of the Presbyterian church. As rector of the Fifth Avenue church in New York City from 1849 until his death ten years later he served a congregation of great wealth, liberality and influence. One of its members was the founder of what is still one of the leading American life insurance companies, the Equitable, and various members of the Alexander family came to hold high-ranking positions in the firm. The mathematician's mother, Elizabeth, was the daughter of one of several who became presidents or vice-presidents of the Equitable. He was also named James Waddell Alexander.

She married John White Alexander (1856-1915), no relation although having the same surname. He was from Pittsburgh, but otherwise not much is known about his antecedents. As a child (he was adopted by a benefactor after his parents died) he already showed artistic promise. In due course he studied painting in Europe and practised successfully in Paris until 1901, when he returned to America. Many commissions for portraits and murals came his way, and he became one of the leading artists practising in America in the early years of the twentieth century. Both in France and in America the Alexanders were socially prominent. In Paris their circle included Claude Debussy, Henry James, Stéphane Mallarme, Auguste Rodin and John Singer Sargent, amongst others. In the 1930's, after her husband died, Elizabeth Alexander's home was known as the meeting-place for everyone who mattered in the art world of New York.

Received by the editors February 16, 2000.

2000 Mathematics Subject Classification. Primary 01A70.

A revised version of this article will appear in my forthcoming book Remarkable Mathematicians. 
Their son, James Waddell Alexander II, the future mathematician, was born 19 September 1888 in Sea Bright, New Jersey. Alexander, as I will now simply call him, received his early education in Paris and at the Browning School in New York. He proceeded to Princeton University in 1906 and graduated in mathematics and physics in 1910, taking a master's degree the following year. In his youth he grew a 'sandy red' beard in keeping with his rather Shavian political views, joined marches on Nassau Street (the main street of Princeton) and spoke from soap-boxes in Trenton. His father painted his portrait several times when he was growing up.

By 1910 Alexander had already become a protégé of Oswald Veblen, the leading topologist in Princeton at that time. After a year as instructor at Princeton he went to Europe in 1912 to visit the Universities of Paris and Bologna. He might have seen Hadamard in Paris and Enriques in Bologna, but this is pure conjecture. There is no record that he went to see Brouwer, although Alexander was to be one of the first to exploit Brouwer's innovative methods in topology, or that he attended the International Congress of Mathematicians held in Cambridge that summer.

On returning to Princeton Alexander belatedly started to write a Ph.D. thesis, under the versatile Swedish-American mathematician T. H. Gronwall. Apparently Veblen thought it too risky for Alexander to offer a thesis on such a novel subject as topology. So instead Alexander wrote what proved to be an important pioneering work in complex analysis on the subject of univalent (schlicht) functions (see [4]) entitled 'Functions which map the interior of the unit circle upon simple regions'. Gronwall, who had been a member of Mittag-Leffler's research group in Stockholm, was an instructor at Princeton in 1913/4 and assistant professor the following year. The thesis, which earned Alexander his Ph.D. in 1915, was published in the Annals of Mathematics the same year. He also published some research on algebraic geometry, including a topological derivation of the Zeuthen-Segre invariant for algebraic surfaces and a proof of the Noether theorem for Cremona transformations.

When Alexander began his topological investigations, Poincaré's organization of the subject had been completed only ten years previously. Brouwer had just shown how entirely new methods could be used to advance the subject further. Veblen had not yet given the Colloquium lectures on which his Analysis Situs, the first textbook on topology, would be based. What Poincaré contributed to the subject was immense, but not always supported by a strong logical foundation. The first contributions of Alexander (in collaboration with Veblen) were to provide the subject with a reasonable element of logic. This led to the famous paper of 1915 establishing the topological invariance of the Betti numbers and torsion coefficients. Although he only dealt with the three-dimensional case, the argument Alexander gave is capable of being easily extended to the general case. However, it must be said that this early work required some revision, as in his memoir of 1926, before it could be regarded as completely satisfactory. An account of all this may be found in Dieudonné [3].

Alexander remained at Princeton for the next two years. When America entered the First World War he served as a lieutenant (later captain) in the U.S. Army Office at the Aberdeen Proving Ground in America and later was sent to Europe. On 11 January 1918, in Washington, he married Natalia née Levitzkaya, a White Russian he met in Paris. After leaving the army Alexander rejoined the Princeton faculty as assistant professor (1920-1926). From 1920 onwards his research was focussed exclusively on topology. The central problem on Poincaré's agenda was 
the classification of manifolds, especially three-dimensional manifolds. For the next ten years Alexander published a series of major papers on this side of the subject.

When Poincaré was studying the homology of manifolds, he at first thought that these invariants might be sufficient to classify manifolds up to homeomorphism. When he discovered that three-dimensional manifolds exist which have the same homology as the three-sphere but different fundamental groups, he then conjectured that homology and the fundamental group might be sufficient. In 1919 Alexander found a family of three-manifolds, the lens spaces, which provided counter-examples. Of course it is still an open question whether there exist simplyconnected three-dimensional manifolds which are not homeomorphic to the sphere.

The next year began with an elegant proof of the Jordan curve theorem, followed by a proof and extension of the Jordan-Brouwer theorem. This led to the famous Alexander duality theorem of 1922 , later extended in various directions, notably into the Pontrjagin duality theorem. This is of great importance, not only in itself, but also because there are contained within it certain anomalies whose resolutions were a major influence in the development of homology theories with different coefficients and later in the development of cohomology theories. The construction known as the Alexander horned sphere also dates from the early twenties. But surely his most important work during this fruitful period is his fundamental memoir on combinatorial topology of 1926, in which he extended and clarified his earlier work on homology theory. For this he was awarded the prestigious Bôcher prize of the American Mathematical Society in 1929.

Towards the end of the 1920's Alexander was becoming increasingly interested in knot theory, and in 1928 he made a fundamental discovery. To a given knot diagram he associated a matrix of polynomials and showed that the equivalence class of this matrix (equivalence having a slightly more extended meaning than the ordinary one) is an invariant of the knot type. From this matrix equivalence he extracted by essentially classical means a sequence of polynomials, particularly the one now called the Alexander polynomial, which is such a sensitive invariant that it readily distinguishes most of the knots found in the knot tables compiled in the nineteenth century. Other polynomial invariants of knots were discovered not long ago.

During this period Alexander had become deeply impressed by the research of Solomon Lefschetz, then engaged in 'planting the harpoon of topology in the whale of algebraic geometry.' In 1924 he persuaded Veblen to bring Lefschetz to Princeton from Kansas, where he had been working in almost complete isolation. Alexander and Lefschetz were opposites in many ways. Years later Hassler Whitney commented on their relationship:

'They naturally had many discussions on topology. But Alexander became increasingly wary of this, for Lefschetz would come out with results, not realizing they had come from Alexander. Alexander was a strict and careful worker, while Lefschetz' mind was always full of ideas swimming together, of origin unknown.'

Nevertheless Alexander and Lefschetz, with Veblen, formed a powerful partnership, attracting to Princeton not only able graduate students but also senior visitors from Europe and elsewhere. Alexander was promoted to associate professor (1926-1928) and full professor (1928-1933), although he only taught part-time and accepted half salary. In the thirties his reputation drew to Princeton many of the leading researchers from Europe: Aleksandroff, Čech, Hopf, and Hurewicz amongst them. In 1933 Alexander and Veblen moved to the new Institute for Advanced 
Study, where Einstein, von Neumann and Weyl had also been recruited. Lefschetz thought he should have been chosen rather than Alexander, and blamed Veblen for this, which embarassed Alexander in turn.

By this time combinatorial topology had come to mean practically everything which was not better regarded as point-set topology. Alexander explained how he viewed the situation in a lecture [1] he gave at the 1932 International Congress of Mathematicians in Zurich:

'Broadly speaking we may say that analysis situs, or topology, deals with the properties of geometrical figures that remain invariant when the figures are subject to arbitrary continuous transformations. There are, however, several different kinds of analysis situs, because there are several distinct ways of interpreting the physical notion of continuity in mathematical language. For example there is what we call point-theoretical analysis situs, which is different in spirit as well as in content from the sort of analysis situs originally proposed by Leibnitz. This branch of the science is essentially an outgrowth of function theory, whereas what Leibnitz had in mind was a new and independent type of mathematics, especially designed to avoid the complications of function theory and to deal directly with the purely quantitative aspects of geometrical problems. No doubt combinatorial analysis situs is more nearly a development of Leibnitz' original idea.

'The vogue for point-theoretical analysis situs seems to be due, in large part, to the predominating influence of analysis on mathematics in general. Nowadays we tend, almost automatically, to identify physical space with the space of three variables and to interpret physical continuity in the classical function theoretical manner. But the space of three variables is not the only possible model of physical space, nor is it a satisfactory model for dealing with certain types of problems. Whenever we attack a topological problem by analytic methods it almost invariably happens that to the intrinsic difficulties of the problem, which we can hardly hope to avoid, there are added certain extraneous difficulties in no way connected with the problem itelf, but apparently associated with the particular type of machinery used in dealing with it.'

In the mid-thirties cohomology was in its infancy. Massey [6] and Whitney [7] have described what happened at the first international conference on topology, held in Moscow in 1935. Both Alexander and Kolmogorov, independently of each other, had just announced very similar formulae for a product in what we would nowadays call cohomology. The formulae were quite strange, ending up in the wrong dimension. However, soon after the conference, Čech and Whitney found the right construction. Although Alexander continued to publish for another decade, his great work was now complete. He gave a somewhat sporadic course of lectures on 'gratings', a theory of his which has not turned out to be important. His last paper on this subject appeared in 1947, after which (as Lefschetz put it) he left the field to the suddenly numerous rising generation.

During the Second World War Alexander worked as a civilian with the Office of Scientific Research and Development for the U.S. Army Air Force. After the end of the war he became more and more of a recluse. In 1948 he asked to become a nonstipendiary permanent member of the Institute rather than professor, but although he retained an office there, he had little contact with his colleagues. Three years later he retired from the Institute and virtually disappeared from the mathematical scene. Tucker, who knew him well, describe: 2 an attempt to persuade Alexander to participate in the retirement symposium he was organizing for Lefschetz: 
'In 1953 when Lefschetz retired and we had a symposium in Lefschetz' honour, I called up Alexander and gave him a special invitation to attend as much of the thing as possible, but to please come if he would to the dinner when we were going to make the presentation to Lefschetz. Alexander said, "Well, I would like to come. But I don't go anywhere where there's a crowd." And he said, "Let me think about it." He said, "I want to come." Then he called about a week beforehand. I didn't talk to him myself. He simply left a message, and it was: Sorry, he couldn't come.'

After his wife's death in 1967 Alexander's health slowly declined. He had earlier suffered from an attack of polio, from which he did not entirely recover. His leftwing political views made him suspect during the McCarthy era. Towards the end of his life he became interested in amateur radio and used to pass the time contacting other enthusiasts throughout the world. He died of pneumonia in the Princeton Hospital on 23 September 1971 at the age of eighty-three, leaving a son (John) and daughter (Irina).

To get a better idea of what Alexander was like, let us return to Tucker's reminiscences:

'(Alexander) was a Princetonian by birth, as well as in terms of his education, both undergraduate and graduate. Then he became a member of the faculty at Princeton. He came of an old Princeton family. He was quite well-to-do, so that it was never really necessary for him to work for his living. He had, in his earlier days, say around 1920, been quite interested in the socialist movement. At that time Norman Thomas was the perennial socialist candidate for the Presidency. Norman Thomas was a Princeton alumnus, very highly thought of by Princetonians whether they agreed with his politics or not. But apparently Alexander did agree with the politics of Norman Thomas. I think at some point Alexander was active as an organizer for the socialist party in and around New York City. I'm trying to describe the flavour of the man. He was very handsome, always nicely dressed, but not in a formal way, in sports clothes. He was very kind to students, but in a rather fatherly way. It was impossible to dislike him in any way, because he was so kind and courteous and thoughtful. But there was no drive, no competitiveness, except possibly in mountain climbing, none in mathematics or academic ways.'

In fact Alexander was one of the outstanding American mountaineers of his generation. He began climbing in Colorado in 1921 with an ascent of Long's Peak and graduated to the Alps two years later. His Alpine record comprises more than 200 climbs, mostly major ascents. As he gained proficiency he was attracted to increasingly difficult objectives, looking for new routes and showing a preference for guideless climbing. Some of his graduate students, such as Leon Cohen and Hassler Whitney, were invited to join him in the Alps, where mathematics would be combined with mountaineering. Although he climbed most of the major peaks, he had a special fondness for the Chamonix area, to which he and Natalia returned year after year. They had a modest chalet at Les Houches. They often climbed together, although she was not an enthusiast, but they also enjoyed the rather haughty French society to be found around Chamonix in the summertime; they were both fluent in the French language. From 1937, however, they seem to have given up these visits to Europe and confined their mountaineering to North America.

Around Princeton Alexander was also celebrated for his prowess in climbing the university buildings, such as the Cleveland Tower. He liked to reach his office on the top floor of Fine Hall by climbing up the outside wall of the building and entering through the window, which he always left ajar for this reason. Moreover it was he 
who insisted that the building must have showers and lockers so that they could be used by people like him for sports such as boxing, tennis and squash. He was an expert skiier and loved baseball.

The Alexanders were certainly wealthy, but they did not live ostentatiously. However, as Tucker remarks, 'He was quite different from the run-of-the-mill professor because he had a nice home over in the west end of town. Graduate students were invited to drop in for Sunday afternoon tea there. There were servants in the home, you know. It was very clearly a home of affluence.'

Compared with most people in the university the Alexanders had much greater social prestige. When they gave parties, the guests would include not only academics but also people from the other Princeton, people who had business interests in Philadelphia or New York and who just lived in Princeton because it's a nice place. There would usually be dancing. Alexander was particularly fond of the tango and used to frequent the Rainbow Room of the Rockefeller Centre where New York society went to dance. He had developed a notation for recording the steps and other movements made by dancers. He was also fond of composing limericks.

By common consent Alexander was a superb lecturer, the best of the Princeton mathematicians. Without any sacrifice of precision he had a natural style which was a pleasure to listen to, although some felt they would have learned more from less elegant lectures. Tucker remarked:

'He was a good teacher, an excellent teacher, but I don't think he enjoyed teaching. He didn't need the salary and found it irksome to be obliged to teach courses he wasn't interested in. Now he was a person who, if he agreed to teach a course, would be very conscientious about it. But he would probably find, if it was an undergraduate course, that there was no textbook to his taste... (then) he would try and work up a set of notes with the help of students, and do without a textbook. But this is a lot of work.'

I have not been able to discover more than a little of Alexander's personal and professional papers; he seldom wrote letters, but being such a perfectionist, he left much of his research unpublished. He served the American Mathematical Society on the Council (1923-1925) and as vice-president (1933-1934). In 1930 he was elected a member of the National Academy of Sciences. He received an honorary degree from Princeton, making four Princeton degrees in all. He was a member of various clubs, including the American Alpine Club.

\section{ACKNOWLEDGEMENTS}

Among the many people who have helped me with this portrait I would especially like to thank Dr. Mary Elizabeth Alexander and Mr. James Waddell Alexander III (granddaughter and grandson of the mathematician), Professor R. C. Gunning, Dr. Dale Johnson 3 Professor Louis H. Kaufmann, Mr. J. Monroe Thorington, and the librarians of the following institutions: the Metropolitan Museum (New York), the Seeley G. Mudd Manuscript Library (Princeton), the Princeton Theological Seminary, the Institute for Advanced Study (Princeton), and The Archives of American Mathematics at the Centre for American History, University of Texas (Austin.) 


\section{ENDNOTES}

1. A list of Alexander's publications is given in [1]. The memoir [5] was actually written by Lefschetz shortly before Alexander died.

2. These quotations are extracts from interviews given by A.L. Tucker as part of the Oral History Project 'The Princeton Mathematical Community in the 1930s'.

3. Dr. Johnson kindly made available to me the notes he made when he interviewed Mrs. Irina Reed, Alexander's daughter, in 1983.

\section{REFERENCES}

[1] J.W. Alexander, Some problems in topology. Verhandlungen des Internationalen Mathematiker Kongresses Zurich, ed. Saxer. Fussli, Zurich and Leipzig (1932), vol. 1, 249-257.

[2] Leon W. Cohen, James Waddell Alexander 1888-1971, Bull. Amer. Math. Soc. 79 (1973), 900-903. MR 47:4753

[3] J.A. Dieudonné, A History of Algebraic and Differential Topology 1900-1960, Birkhäuser, Boston (1989). MR 90g:01029

[4] Alan Gluchoff and Frederick Hartmann, On a 'much underestimated paper' of Alexander, Arch. Hist. Exact Sciences 55 (2000), 1-41. CMP 2000:17

[5] Solomon Lefschetz, James Waddell Alexander (1888-1971), Biogr. Mem. Amer. Phil. Soc. 79 (1973), Philadelphia (1974), 663-680.

[6] W.S. Massey, A history of cohomology theory, in History of Topology, ed. James, North Holland, Amsterdam (1999), 579-604. MR 2000i:55001]

[7] Hassler Whitney, Moscow 1935: Topology Moving toward America, in A Century of Mathematics in America, ed. Duren, Amer. Math. Soc., Providence, R.I. (1988), vol. I, 97-117. MR 90g:01043

Mathematical Institute, University of Oxford, 24-29 St. Giles, Oxford OX1 3LB, UK

E-mail address: imj@maths.ox.ac.uk 